\title{
Application of the Bio-Active Beads Method in Rice Transformation
}

\author{
Haibo LIU ${ }^{1}$, Akira KAWABE ${ }^{1}$, Sachihiro MATSUNAGA ${ }^{1}$, Akio KOBAYASHI ${ }^{1}$, Satoshi HARASHIMA ${ }^{1}$, \\ Susumu UCHIYAMA ${ }^{1}$, Nobuko OHMIDO ${ }^{2}$ and Kiichi FUKUI ${ }^{1}$ \\ ${ }^{\prime}$ Department of Biotechnology, Graduate School of Engineering, Osaka University 2-1 Yamadaoka, \\ Suita, Osaka 565-0871, Japan. \\ ${ }^{2}$ Faculty of Human Development, Kobe University, Tsurukabuto 3-11, Hyogo 657-8501, Japan. \\ *Corresponding author E-mail address: kfukui@bio.eng.osaka-u.ac.jp
}

Received 7 July 2004 ; accepted 23 July 2004 (Edited by H. Sano)

\begin{abstract}
The bio-active beads system has been verified as a novel transformation method. To enhance its versatility, we applied this method to the transformation of a monocot plant, rice. The transient GFP expression was observed $24 \mathrm{~h}$ after transformation. This indicates that the method can also be applied to monocotyledons.
\end{abstract}

Key words: Bio-active beads system, Monocotyledons, Transformation.

The production of genetically transformed plant tissues and plants is the focus of experimental plant science and the basis of agricultural biotechnology (Taylor and Fauquet 2002). Genetic engineering of monocotyledons has always been of great interest due to its potential benefits to crop improvement and subsequently to human nutrition (Dale et al., 1993). Rice is not only an important food crop but also a model plant among monocotyledons because of its small genome size (Kurata and Fukui, 2003). The transfer of useful genes into rice is still a potential research area to enhance agricultural production. However, monocotyledonous plants are generally more recalcitrant to genetic transformation than dicotyledonous species because of the absence of reliable Agrobacterium-mediated transformation methods and the difficulties associated with the culture of monocotyledonous tissues in vitro (Vain et al., 1995). Cereals are not natural hosts for Agrobacterium species and only recently has it been possible to achieve cereal transformation by this method (Kohli et al., 2003). Rice is the first species to be transformed by Agrobacterium among cereals (Chan et al., 1992). Successful transformation was successively reported for maize (Ishida et al., 1996), barley (Tingay et al., 1997), wheat (Cheng et al., 1997), and sorghum (Zhao et al., 2000). Despite these promising results, several difficulties such as host specificity and low efficiency remain associated with this strategy. A number of direct DNA transformation methods have also been attempted to transform the monocot- yledon. Rice transformation by electroporation (Shimamoto et al., 1989) and microinjection (Saito et al., 2003) methods has been reported. However, the same problems including low transformation efficiency and difficulty in manipulation still exist. Particle bombardment has solved the problem of efficiency. However, it results in the integration of multiple, often rearranged, copies of the transgene (Wisniewski et al., 2002). The further evolution of monocotyledon transformation technologies would therefore appear to depend on the development of techniques that allow controlled integration and expression of foreign DNA into the plant genome.

A novel and efficient transformation system, the bio-active beads system for DNA delivery/expression with a capacity to transport DNA of high molecular weight was previously reported (Sone et al., 2002). This method had been applied to the transformation of yeast, and the physical stabilization of the yeast chromosomal DNA immobilized on bio-active beads had been evaluated (Mizukami et al., 2003). This method was also applied for transforming mammalian cells (Higashi et al., 2004). By means of this method, transformed tobacco SR-1 plants, the transformation being confirmed by screening for Kanamycin resistance were successfully obtained (Liu et al., 2004a). Additionally, a 124-kbYAC had been transferred into tobacco BY -2 cells for finding common promoter (Liu et al., 2004b). The transformation capability of this new system has been noticed recently. In order to understand the extent of the application of this new 
transformation system, we applied it to rice transformation, to confirm whether the bio-active beads method can be applied to monocotyledons.

The procedure for the production of bio-active beads including pUC18-sGFP (Niwa et al., 1999) has been described previously (Sone et al, 2002; Mizukami et al., 2003; Higashi et al., 2004; Liu et al., 2004a, b). The pUC18-sGFP $(4.1 \mathrm{~kb})$ of plasmid contains CaMV35S promoter, sGFP coding sequence, and NOS 3 terminal was used for observation of transient expression. The rice seeds (Oryza sativa L. ssp. Japonica cv. Nipponbare) were surface -sterilized with $70 \%$ ethanol for $10 \mathrm{~min}$ and sodium hypochlorite solution for $10 \mathrm{~min}$. The procedure for callus induction, and preparation of the callus suspension culture was similar to a previous protocol (Lee et al., 1991). Rice protoplasts were prepared according to the previously specified procedure with several modifications (Shimamoto et al., 1989). Since the commercial cellulose Onozuka RS and the commercial pectate lyase Pectolyase $\mathrm{Y}-23$ are widely used as enzymes for protoplast formation, we also used both these enzymes, however, the enzyme concentration was modified. A $40 \mathrm{ml}$ enzyme mixture solution consisting of $0.1 \%\left(\mathrm{w} \mathrm{v}^{-1}\right)$ pectolyase $\mathrm{Y}-23$ (Kikkoman, Tokyo), 4\% $\left(\mathrm{w} \mathrm{v}^{-1}\right)$ Cellulase Onozuka RS (Yakult, Tokyo), $0.02 \%$ (w $\left.\mathrm{v}^{-1}\right) \mathrm{CaCl}_{2}, 0.2 \%\left(\mathrm{w} \mathrm{v}^{-1}\right) \mathrm{k}$-dextran sulfate, and $18 \%\left(\mathrm{w} \mathrm{v}^{-1}\right)$ mannitol was kept for $3 \mathrm{~h}$ at $30^{\circ} \mathrm{C}$ with shaking. The protoplasts were then harvested by centrifugation at $800 \mathrm{rpm}$ for $5 \mathrm{~min}$. Twenty-five milliliters rice washing medium and $25 \mathrm{ml} \mathrm{W} 5$ solution was used to separate the enzyme after the centrifugation. The protoplasts and the bio-active beads were mixed with polyethylene-glycol (PEG) according to the protocol described (Sone et al., 2002; Liu et al., 2004a). The PEG treatment time was about $30 \mathrm{~min}$ in the dark.

After the $24 \mathrm{~h}$ transformation, we observed transient green fluorescent protein (GFP) expression under an inverted fluorescence microscope (Fig. 1).
The signal intensity was almost similar to the transient GFP expression observed in tobacco BY-2 (Liu et al., 2004b). This indicates that the expressed GFP gene coincides with the gene in transformed tobacco cells. The transformation efficiency is about $2.2 \times 10^{-5}$ after repeating the experiment four times (Table 1). When the transformation was performed using only the PEG treatment without bio-active beads, no transient expression was observed in the tobacco cells. Treatment with twice the concentration of the enzyme would result in the formation of approximately 5-7 times the number of protoplasts. However, there was no obvious increase in the transformation efficiency with an increase in the number of protoplasts. The treatment by high concentration of enzyme maybe brings some damages to the protoplast and effects the transformation efficiency. Compared with the traditional method, the efficiency of our method is not higher than the bombardment and electroporation methods (Saito et al., 2003; Lee et al., 1991). Nevertheless, the transient GFP expression indicates that we had successfully transferred plasmid pUC18 - sGFP into rice protoplasts by the bio-active beads method.

The bio-active beads can protect the DNA molecule and keep it intact from damage during the transfer into the target cells (Mizukami et al., 2003). This transfer mechanism is more suitable for the delivery of large size molecules. For example, it will realize the YAC or BAC carrying multiple gene transfer into plant cells collectively. As most agronomic characteristics are polygenic in nature, plant genetic engineering will require the manipulation of complex metabolic or regulatory pathways involving multiple genes or gene complexes (Chen et al., 1998). Therefore, applying the bio-active beads system to the monocotyledons will prove to be tremendously advantageous to agronomic transgene studies.

Although the transformation efficiency was not
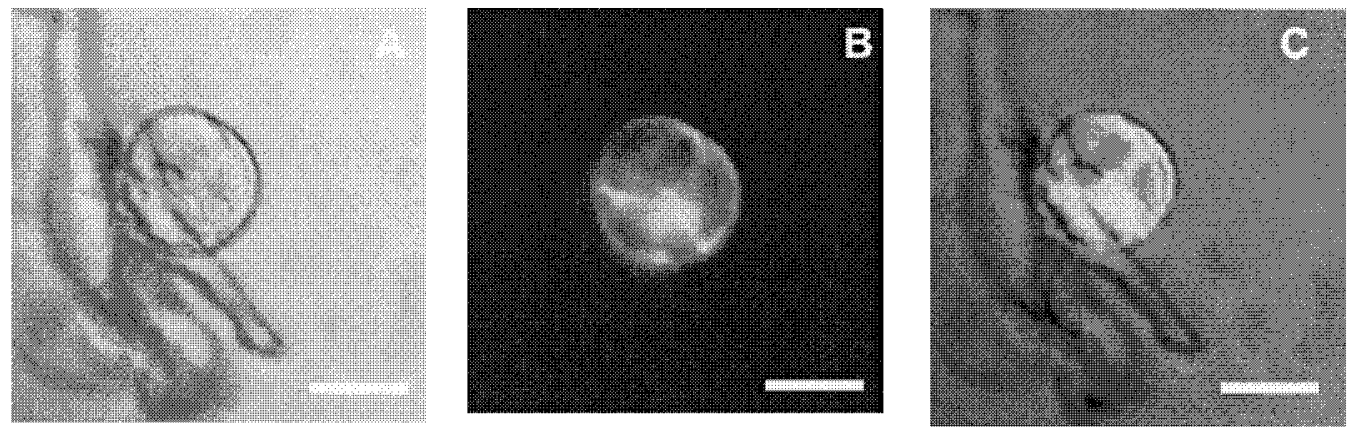

Fig. 1 Transient GFP expression $24 \mathrm{~h}$ after transformation of rice protoplasts. (A) Phase contrast image of the protoplast; (B) Fluorescent image of the transient expression of GFP after the transformation; (C) Merged image. The bars $=10 \mu \mathrm{m}$. 
Table 1 Transient GFP expression of rice protoplasts.

\begin{tabular}{ccccc}
\hline Experiment & $\begin{array}{c}\text { Concentration of } \\
\text { enzyme }\end{array}$ & $\begin{array}{c}\text { Transient GFP } \\
\text { expression }\end{array}$ & $\begin{array}{c}\text { Total number of } \\
\text { protoplasts }\end{array}$ & Efficiency \\
\hline $1-\mathrm{A}$ & $1 \times$ & 2 & $1 \times 10^{5}$ & $2.0 \times 10^{-5}$ \\
$1-\mathrm{B}$ & $1 \times$ & 1 & $1 \times 10^{5}$ & $1.0 \times 10^{-5}$ \\
$2-\mathrm{A}$ & $2 \times$ & 22 & $5 \times 10^{5}$ & $4.4 \times 10^{-5}$ \\
$2-\mathrm{B}$ & $2 \times$ & 8 & $5 \times 10^{5}$ & $1.6 \times 10^{-5}$ \\
$3-\mathrm{A}$ & $2 \times$ & 13 & $5 \times 10^{5}$ & $2.6 \times 10^{-5}$ \\
$3-\mathrm{B}$ & $2 \times$ & 9 & $5 \times 10^{5}$ & $1.8 \times 10^{-5}$ \\
$4-\mathrm{A}$ & $2 \times$ & 19 & $7 \times 10^{5}$ & $2.7 \times 10^{-5}$ \\
$4-\mathrm{B}$ & $2 \times$ & 12 & $7 \times 10^{5}$ & $1.7 \times 10^{-5}$ \\
\hline Total & - & - & $36 \times 10^{5}$ & - \\
\hline Average & - & - & $2.2 \times 10^{-5}$ \\
\hline $1 \times:$ enzyme concentration: $0.05 \%\left(\mathrm{w} \mathrm{v}^{-1}\right)$ pectolyase $\mathrm{Y}-23,2 \%\left(\mathrm{w} \mathrm{v}^{-1}\right)$ Cellulase Onozuka RS, $0.01 \%\left(\mathrm{w} \mathrm{v}^{-1}\right)$ \\
$\mathrm{CaCl}_{2}, 0.1 \%\left(\mathrm{w} \mathrm{v}^{-1}\right) \mathrm{k}$ - dextran sulfate, and $9 \%\left(\mathrm{w} \mathrm{v}^{-1}\right)$ mannitol; \\
$2 \times:$ enzyme concentration: $0.1 \%\left(\mathrm{w} \mathrm{v}^{-1}\right)$ pectolyase $\mathrm{Y}-23,4 \%\left(\mathrm{w} \mathrm{v}^{-1}\right)$ Cellulase Onozuka RS, $0.02 \%\left(\mathrm{w} \mathrm{v}^{-1}\right)$ \\
$\mathrm{CaCl}_{2}, 0.2 \%\left(\mathrm{w} \mathrm{v}^{-1}\right) \mathrm{k}$ - dextran sulfate, and $18 \%\left(\mathrm{w} \mathrm{v}^{-1}\right)$ mannitol.
\end{tabular}

sufficiently high when the bio-active beads method was used in the rice transformation, the characteristics of this method, such as a high carrying capability of large DNA molecules and extensive application to different species still bestow a potential benefit to studies in gene delivery.

We attempted to apply the bio-active beads method to monocotyledons for the first time, and the extensive application capability was reconfirmed. The expected advantage of this method will be challenged while attempting the transfer of wheat genes into the rice genome for crop evolution.

\section{Acknowledgements}

We would like to thank Satoru Fujimoto and Masataka Yonemura for their valuable suggestions during this study. A part of study was supported by the fund "Development of a novel transformation system for plant using laser manipulation techniques" Basic Research Activities for Innovative Biosciences, Japan granted to K. F.

\section{References}

Chan, M. T., Lee, T. M. and Chang, H. H., 1992. Transformation of indica rice (Oryza sativa) mediated by Agrobacterium tumefaciens. Plant Cell Physiol., 33: $577-583$.

Chen, L., Marmey, P., Taylor, N. J., Brizard, J. P., Espinoza, C., D'Cruz, P., Huet, H., Zhang, S., Kochko, A., Beachy, R. N., and Fauquet, C., 1998. Expression and inheritance of multiple transgenes in rice plants. Nature Biotechnol., 16: 1060-1064.

Cheng, M., Fry, J.E., Pang, S.Z., Zhou, H.P., Hironaka, C.
M., Duncan, D.R., Conner, T.W. and Wan, Y.C., 1997. Genetic transformation of wheat mediated by Agrobacterium tumefaciens. Plant Physiol., 115: 971-980.

Dale, P. J., Irwin, J. A. and Scheffler, J. A., 1993. The experimental and commercial release of transgenic crop plants. Plant breeding, 111: 1- 22.

Higashi, T., Nagamori, E., Sone, T., Matsunaga, S. and Fukui, K., 2004. A novel transfection method for mammalian cells using calcium alginate microbeads. J. Biosci. Bioeng, 97: 191- 195.

Ishida, Y., Saito, H., Ohta, Y., Komari, T., and Kumashiro, T., 1996. High efficiency transformation of maize (Zea mays) mediated by Agrobacterium tumefaciens. Nature Biotechnol., 14: 745-750.

Kohli, A., Twyman, R. M., Abranches, R., Wegel, E., Stoger, E., and Christou, P., 2003. Transgene integeration, organization and interaction in plants. Plant Mol. Biol., 52: 247-258.

Kurata, N. and Fukui, K., 2003. Chromosome reseatch in genus Oryza. In J. S. Nanda and S. D. Sharma (Eds.) Monograph in genus Oryza, pp. 213-261. Science publishers, New Hampshire.

Lee, N., Wang, Y., Yang, J., Ge, K., Huang, S., and Tan J. 1991. Efficient transformation and regeneration of rice small cell groups. Proc. Natl. Acad. Sci. USA, 88: 6389 $-6393$.

Liu, H., Kawabe, A., Matsunaga, S., Murakawa, T., Mizukami, A., Yanagisawa, M., Nagamori, E., Harashima, S., Kobayashi, A., and Fukui, K., 2004(a). Obtaining transgenic plants using the bio-active beads method. J. Plant Res., 117: 95-99.

Liu, H., Kawabe, A., Matsunaga, S., Kim, Y. H., Higashi, T., Uchiyama, S., Harashima, S., Kobayashi, A., and Fukui, K., 2004(b). An Arabidopsis thaliana gene on the yeast artificial chromosome can be transcribed in tobacco cells. Cytologia, 69: 235-240. 
Mizukami, A., Nagamori, E., Takakura, Y., Matsunaga, S., Kaneko. Y., Kajiyama, S., Harashima, S., Kobayashi, A., and Fukui, K., 2003. Transformation of yeast using calcium alginate microbeads with surface-immobilized chromosomal DNA. BioTechniques, 35: 734-740.

Niwa, Y., Hirano, T., Yoshimoto, K., Shimizu, M., and Kobayashi, H., 1999. Non-invasive quantitative detection and applications of non-toxic, S65T-type green fluorescent protein in living plants. Plant J., 18: 455463.

Saito, M., Mukai, Y., Komazaki, T., Oh, K. B., Nishizawa, Y., Tomiyama, M., Shibuya, N., and Matsuoka, H., 2003. Expression of rice chitinase gene triggered by the direct injection of $\mathrm{Ca}^{2+}$. J. Biotechnol., 105: 41-49.

Shimamoto, K., Terada, R., Izawa, T., and Fujimoto, H. 1989. Fertile transgenic rice plants regenerated from transformed protoplasts. Nature, 338: 274- 276.

Sone, T., Nagamori, E., Ikeuchi, T., Mizukami, A., Takakura, Y., Kajiyama, S., Fukusaki, E., Harashima, S., Kobayashi, A., and Fukui, K, 2002. A novel gene delivery system in plant with calcium alginate micro- beads. J. Biosci. Bioeng, 94: 87-91.

Taylor, N. J. and Fauquet, C. M., 2002. Microparticle bombardment as a tool in plant science and agricultural biotechnology. DNA and Cell Biol., 21: 963-977.

Tingay, S., Mcelroy, D., Kalla, R., Fieg, S., Wang, M. B., Thornton, S. and Brettell, R., 1997. Agrobacterium tumefaciens-mediated barley transformation. Plant J., 11: $1369-1376$.

Vain, P., De Buyser, J, Bui Trang, V., Haicour, R., and Henry, Y., 1995. Foreign gene delivery into monocotyledonous species. Biotechnol. Adv., 13: 653-671.

Wisniewski, J. P., Frangne, N., Massonneau, A., and Dumas. C., 2002. Between myth and reality: genetically modified maize, an example of a sizeable scientific controversy. Biochimie, 84: $1095-1103$.

Zhao, Z. Y., Cai, T. S., Tagliani, L., Miller, M., Wang, N., Pang, H., Rudert, M., Schroeder, S., Hondred, D., Seltzer, J, and Pierce, D., 2000. Agrobacterium-mediated sorghum transformation. Plnat Mol. Biol., 44: $789-798$. 